\title{
Pengontrolan Level Air Dan Pendeteksi Kekeruhan Kolam Ikan Berbasis Mikrokontroler
}

\author{
Anton Hidayat $^{1}$, Suryadi $^{2}$, Dwivo Arestu Yendrial ${ }^{3}$ \\ ${ }^{123}$ Jurusan Teknik Elektro Politeknik Negeri Padang \\ antonhidayat@pnp.ac.id \\ Kampus Politeknik Negeri Padang, Limau Manis Padang
}

\begin{abstract}
The number of freshwater fish ponds found in the Sweet Lemon area of Pauh District, Padang City is due to the presence of water dams made by the government for irrigating rice fields so that it is used by the community to collect freshwater fish both in front of homes and unproductive fields, because of abundant water sources. will be water for fish pond farmers in the sweet limes of Pauh sub-district, Padang City is not a problem. But the problem will occur if the rain falls where the water in the dam will increase so that this will increase the amount of debit of water entering the fish pond, this becomes a problem for pond farmers because the fish will easily die, the fish will come out and also the fish will be diseased due to the many debits of water in a pool due to cloudy water. Based on these problems I tried to make a device using a microcontroller that can be set using the keypad and control the water level using an ultrasonic sensor and the level of turbidity of water in a jetted pool displayed on the LCD automatically by setting open and close the pool water so that the pool water level can arranged as needed. How to regulate the position of a DC motor can be used by using a microcontroller so that farmers in jetted fish can monitor water conditions in the pond and also be able to regulate water levels that will enter the pool automatically, to increase fish yields and prevent fish deaths due to water conditions that are not well.
\end{abstract}

Keywords: ATMega328 Microcontroller, Ultrasonic Sensor, Photodiode Sensor, LCD, Keypad, DC Motor

Abstrak - Banyaknya tambak ikan air tawar yang terdapat di daerah limau Manis Kecamatan Pauh Kota Padang ini disebabkan adanya bendungan air yang dibuat pemerintah untuk pengairan sawah sehingga dimanfaatkan oleh masyarakat untuk berkolam ikan air tawar baik didepan rumah maupun diladang yang tidak produktif, karena sumber air berlimpah sehingga kebutuhan akan air bagi petani tambak ikan di limau manis kecamatan Pauh Kota Padang tidaklah menjadi masalah. Namun permasalahan akan terjadi bila hujan turun dimana air pada bendungan akan meningkat sehingga ini akan meningkatkan jumlah debet air yang masuk pada kolam ikan, ini menjadi permasalahan bagi petani tambak karena ikan akan mudah mati, ikan akan keluar dan juga ikan akan berpenyakit disebabkan banyaknya debet air dalam kolam di karenakan air keruh. Berdasarkan permasalahan tersebut saya mencoba membuat sebuah alat menggunakan mikrokontroler yang dapat diatur menggunakan keypad dan mengontrol level air menggunakan sensor ultrasonik serta tingkat kekeruhan air pada kolam air deras ditampilkan pada LCD secara otomatis dengan cara mengatur buka tutup pintu keluar air kolam sehingga tinggi level air kolam dapat diatur sesuai kebutuhan. Cara mengatur posisi motor DC dapat dimanfaatkan dengan menggunaakan mikrokontroler agar petani tambak ikan air deras dapat memantau kondisi air pada kolam dan juga dapat mengatur ketinggian air yang akan masuk keluar kolam secara otomatis, guna meningkatkan hasil panen ikan serta mencegah kematian ikan akibat kondisi air yang tidak baik.

Kata kunci: Mikrokontroler ATMega328, Sensor Ultrasonik, Sensor Photodioda, LCD, Keypad, Motor DC

(C) 2017 Elektron Jurnal Ilmiah

\section{PENDAHULUAN}

Tambak ikan air deras banyak terdapat di daerah limau Manis kecamatan Pauh Kota Padang dimana banyak petani menjadikan tambak ikan merupakan mata pencaharian hidup. Banyaknya tambak ikan air tawar dengan air mengalir pada daerah limau manis ini disebabkan adanya bendungan air yang dibuat pemerintah untuk pengairan sawah sehingga dimanfaatkan oleh masyarakat untuk berkolam ikan air tawar baik didepan rumah maupun diladang yang tidak produktif, karena sumber air melimpah sehingga kebutuhan akan air bagi petani tambak dilimau manis tidaklah menjadi masalah.
Namun permasalahan akan terjadi bila hujan turun dimana air pada bendungan akan meningkat sehingga ini akan meningkatkan jumlah debet air yang masuk pada kolam ikan dan juga akan menumpuknya sampah pada kolam, ini menjadi permasalahan bagi petani tambak karena ikan akan mudah mati, ikan akan keluar dan juga ikan akan berpenyakit disebabkan banyaknya debet air dalam kolam oleh karena itu bagi petani bila hujan turun para petani tambak ikan akan segera munutup pintu air yang masuk kedalam kolam agar ikan tidak mati dan debet air yang banyak tidak masuk kedalam kolam dengan menyebabkan ikan akan mudah keluar. Berdasarkan permasalahan tersebut pada penelitian ini dikembangkanlah Alat Pengontrolan Level Air dan Pendeteksi Kekeruhan Kolam Ikan 
Berbasis Mikrokontroller. Beberapa penelitian yang terkait perlah dilakukan sebelumnya. Rayza dkk [1] telah membuat pengontrolan tinggi kolam ikan menggunakan Raspberry $\mathrm{Pi}$ dan komputer. Menggunakan LDR untuk mendeteksi kekeruhan air Tegar dkk[2] membuat pengontrolan tinggi kolam ikan. Pada penelitian ini mikrokontroler digunakan untuk pengaturan pintu air kolam sedangkan photodiode digunakan untuk mendeteksi kekeruhan air. Pintu air kolam secara otomatis dapat digunakan oleh petani tambak ikan air deras untuk mengatur ketinggian air yang akan masuk kedalam kolam dari guna meningkatkan hasil panen ikan dan juga mencegah kematian ikan akibat kondisi air yang tidak baik.

\section{METODE PENELITIAN}

Alat pengontrolan kolam ikan ini menggunakan mikrokontroller Arduino Uno sebagai pengontrol utama dari rangkaian-rangkaian elektronika yang digunakan, Arduino Uno ini memiliki input sebagai masukan dan output sebagai keluaran yang dapat mengendalikan komponen-komponen dan peralatan elektronika. Dalam pembuatan tugas akhir ini, digunakan keypad sebagai masukan setting point, sensor ultrasonik untuk pengukur ketinggian, dan sensor photodioda untuk pengukur kekeruhan air pada kolam serta untuk output motor DC untuk memutar ulir guna membuka dan menutup pintu air kolam, kemudian output LCD untuk menampilkan nilai setting point, nilai kekeruhan, dan ketinggian kolam. Proses kerja alat dapat dilihat blok diagram pada gambar 1 .

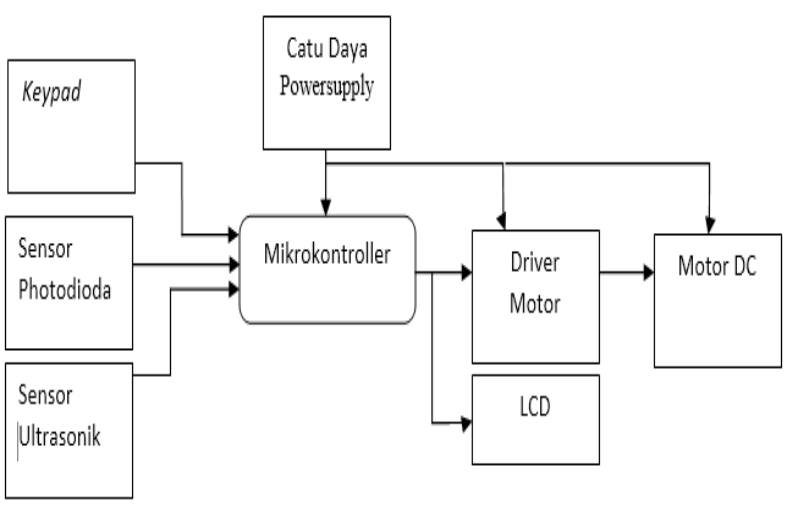

Gambar 1. Blok Diagram Secara Keseluruhan

Prinsip kerja pada Pengontrolan Kolam Ikan Otomatis ini yaitu Air yang berada di dalam kolam akan dideteksi kejernihannya menggunakan sensor photodioda. Kemudian air di dalam kolam akan diatur ketinggiannya sesuai keinginan menggunakan sensor ultrasonik sebagai pengatur level air. Selanjutnya air tersebut diatur buka tutup pintu air keluar sehingga air tersebut sesuai berdasarkan ketinggian yang diinginkan tersebut dengan gabungan sistem dari sensor ultrasonik dan motor DC yang dirakit untuk membuka dan menutup pintu air keluar.

\subsection{Perancangan Hardware}

Pada rancangan ini sensor photodioda digunakan untuk mendeteksi warna. Sensor ini mendeteksi kejernihan air yang ada didalam kolam kemudian ditampilkan di LCD. Terdapat 3 buah pin yaitu pin1 adalah input sumber tegangan $+5 \mathrm{~V}$ DC, pin 2 adalah output nilai yang terbaca pada photodioda, dan pin 3 adalah Ground, seperti yang terlihat pada gambar 2.

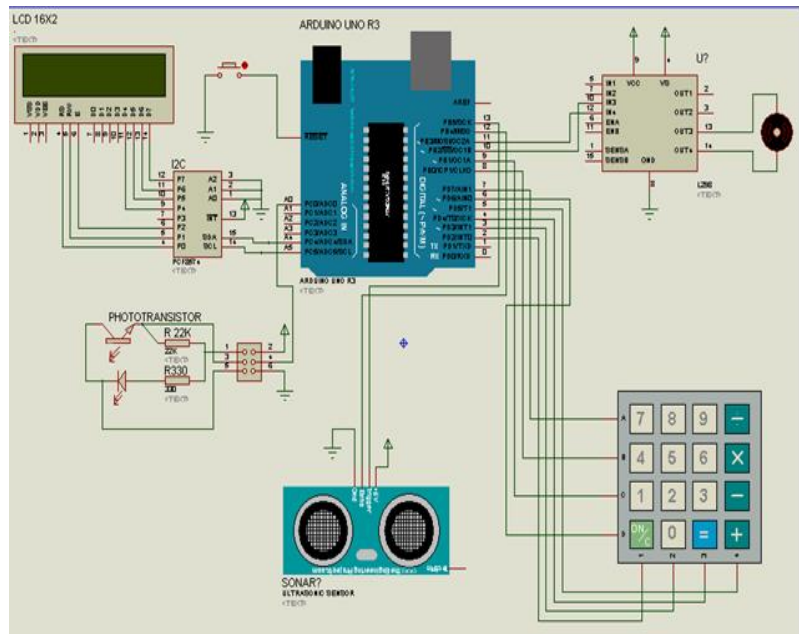

Gambar 2. Rangkaian elektronika keseluruhan alat

Liquid Crystal Display berfungsi sebagai tampilan Setting Point, nilai kekeruhan air, dan ketinggian air. LCD tersebut akan dihubungkan ke I2C terlebih dahulu kemudian ke Arduino Atmega 328. Pemasangan ke arduino yaitu pada pin A4(SDA), A5(SCL), +5V DC dan ke Ground . Rangkaian Ultrasonik berfungsi sebagai pembaca jarak. Pada kolam ikan berfungsi untuk membaca ketinggian air di dalam kolam dengan menggunakan paralon yang diberi pelampung agar pembacaan sensor lebih akurat. Pemasangan ke Arduino yaitu trigger ke pin digital 13, echo ke pin digital 12, +5V DC, dan Ground. Rangkaian Keypad berfungsi sebagai memasukkan nilai input ke Arduino. Pada Pengontrolan Kolam Ikan digunakan sebagai setting point untuk menentukan ketinggian air yang diinginkan. Pemasangan ke Arduino yaitu dipasang di pin digital yaitu pin 2, pin 3, pin 4, pin 5, pin 6, pin 7, pin 8, dan pin 9. Rangkaian Driver Motor berfungsi sebagai pengatur putaran motor DC untuk membuka dan menutup pintu air kolam. Pemasangan ke Arduino yaitu dipasang di pin digital 10, 11 dan $+12 \mathrm{~V} \mathrm{DC}$, Ground.

\subsection{Perancangan Software}

Flowchart proses kerja alat pengontrolan level air dan pendeteksi kekeruhan air dapat dilihat pada gambar 3. Proses dimulai dari inisialisasi Keypad, Ultrasonik, Photodioda. Selanjutnya dilakukan pengaturan set point menggunakan keypad. Jika nilai set point melebihi dari nilai yang ditetapkan maka motor DC berputar membuka pintu air. Jika nilai set point kurang dari nilai yang ditetapkan maka motor DC berputar 
menutup pintu air. Selanjutnya jika Jika nilai set point sama dari nilai yang ditetapkan maka motor DC berhenti berputar.

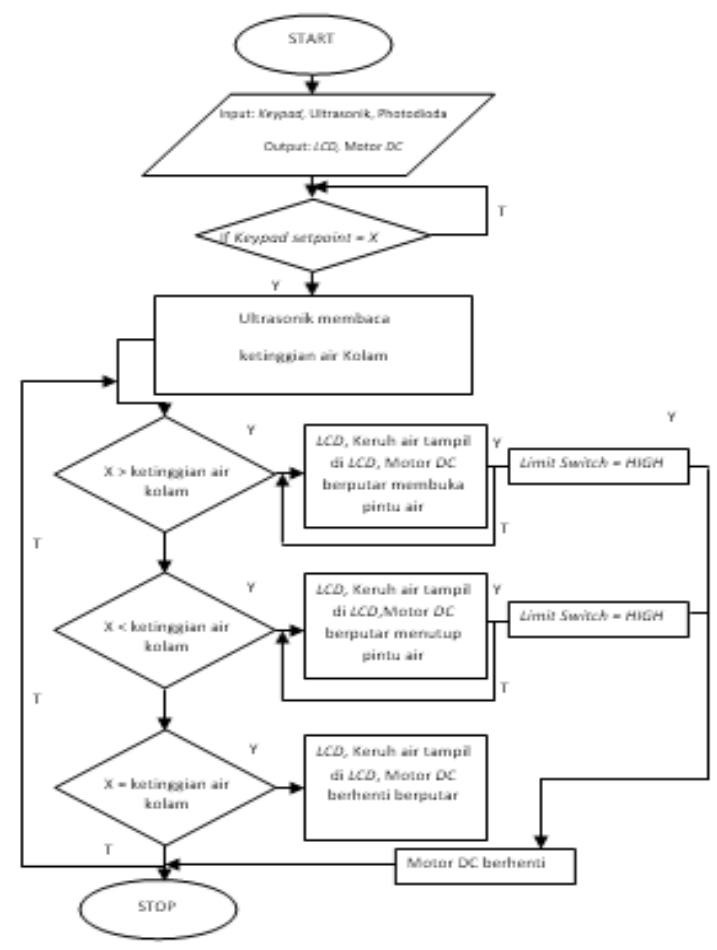

Gambar 3. Flow Chart

\section{HASIL DAN PEMBAHASAN}

Pada bagian ini akan diperlihatkan hasil pengujian alat yang telah dibuat. Pertama pengujian sensor secara keseluruhan. Selanjutnya pengujian motor DC berdasarkan ketinggian Gambar 4 merupakan gambar alat secara keseluruhan

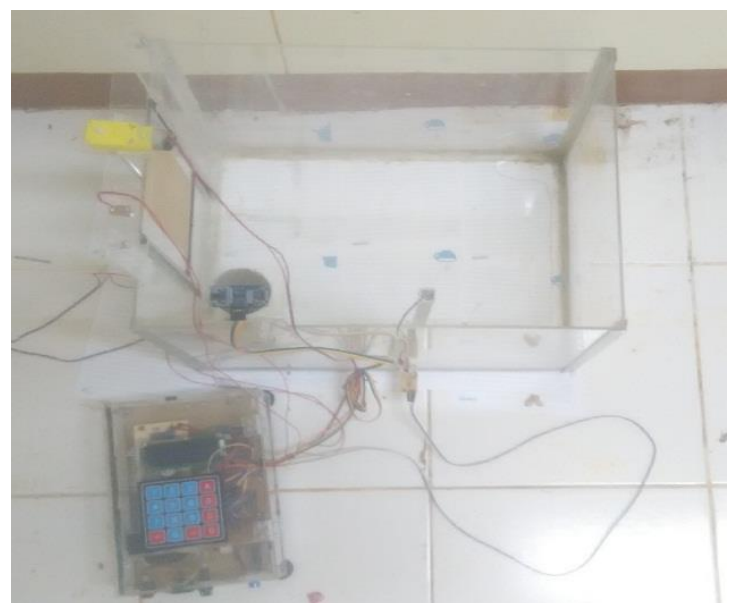

Gambar 4. Pengontrolan Level Air Dan Pendeteksi Kekeruhan Kolam Ikan

\subsection{Pengujian Sensor Ultrasonik}

Setelah dilakukan pengukuran dan pengujian, maka didapat hasil seperti yang terlihat pada Tabel 1 berikut ini.

Tabel 1. Hasil Pengujian Sensor Ultrasonic

\begin{tabular}{|c|c|c|c|}
\hline No. & $\begin{array}{c}\text { Jarak } \\
\text { Menggunakan } \\
\text { Meteran }\end{array}$ & $\begin{array}{c}\text { Jarak } \\
\text { Menggunakan } \\
\text { Sensor Ultrasonik }\end{array}$ & Error \\
\hline 1. & $5 \mathrm{~cm}$ & $5,28 \mathrm{~cm}$ & $0,28 \mathrm{~cm}$ \\
\hline 2. & $10 \mathrm{~cm}$ & $10,29 \mathrm{~cm}$ & $0,29 \mathrm{~cm}$ \\
\hline 3. & $20 \mathrm{~cm}$ & $19,48 \mathrm{~cm}$ & $0,52 \mathrm{~cm}$ \\
\hline 4. & $30 \mathrm{~cm}$ & $30,82 \mathrm{~cm}$ & $0,82 \mathrm{~cm}$ \\
\hline 5. & $40 \mathrm{~cm}$ & $39,81 \mathrm{~cm}$ & $0,19 \mathrm{~cm}$ \\
\hline 6. & $50 \mathrm{~cm}$ & $49,94 \mathrm{~cm}$ & $0,06 \mathrm{~cm}$ \\
\hline 7. & $60 \mathrm{~cm}$ & $59,70 \mathrm{~cm}$ & $0,30 \mathrm{~cm}$ \\
\hline 8. & $70 \mathrm{~cm}$ & $68,63 \mathrm{~cm}$ & $1,37 \mathrm{~cm}$ \\
\hline 9. & $80 \mathrm{~cm}$ & $78,43 \mathrm{~cm}$ & $1,57 \mathrm{~cm}$ \\
\hline 10. & $90 \mathrm{~cm}$ & $88,13 \mathrm{~cm}$ & $1,87 \mathrm{~cm}$ \\
\hline 11. & $100 \mathrm{~cm}$ & $97,88 \mathrm{~cm}$ & $2,12 \mathrm{~cm}$ \\
\hline 12. & $110 \mathrm{~cm}$ & $107,07 \mathrm{~cm}$ & $2,93 \mathrm{~cm}$ \\
\hline 13. & $120 \mathrm{~cm}$ & $117 \mathrm{~cm}$ & $3 \mathrm{~cm}$ \\
\hline 14. & $130 \mathrm{~cm}$ & $126 \mathrm{~cm}$ & $4 \mathrm{~cm}$ \\
\hline 15. & $140 \mathrm{~cm}$ & $136,62 \mathrm{~cm}$ & $3,38 \mathrm{~cm}$ \\
\hline 16. & $150 \mathrm{~cm}$ & $145,96 \mathrm{~cm}$ & $4,04 \mathrm{~cm}$ \\
\hline
\end{tabular}

Dari hasil pengukuran yang dilakukan diperoleh hasil dari tabel di atas diketahui bahwa Sensor Ultrasonik sebagai pengukuran jarak memiliki error $0,28 \mathrm{~cm}$ sampai 4,04 cm dibandingkan dengan alat ukur. Ratarata error yang dihasilkan oleh perbandingan tersebut yaitu 26,74 / $16=1,67 \mathrm{~cm}$ dan bisa mempengaruhi ketinggian kolam yang diinginkan karena semakin jauh jarak yang dibaca maka semakin besar juga nilai error yang dihasilkan oleh perbandingan tersebut.

\subsection{Pengujian Sensor Photodioda}

Hasil pengukuran dan pengujian dapat dilihat pada tabel 2.

\begin{tabular}{cc}
\hline $\begin{array}{c}\text { Air Uji (Air } \\
\text { Kolam) }\end{array}$ & $\begin{array}{c}\text { Nilai } \\
\text { ADC }\end{array}$ \\
\hline Murni & 543 \\
\hline Tanah Liat 1 & 546 \\
\hline Tanah Liat 2 & 550 \\
\hline Tanah Liat 3 & 557 \\
\hline Tanah Liat 4 & 563 \\
\hline Tanah Liat 5 & 571 \\
\hline Tanah Liat 6 & 577 \\
\hline Tanah Liat 7 & 581 \\
\hline Tanah Liat 8 & 585 \\
\hline Tanah Liat 9 & 589
\end{tabular}


Tabel 3 Hasil Pengujian Sensor Photodioda untuk Jenis Ikan

\begin{tabular}{cc}
\hline $\begin{array}{c}\text { Air untuk jenis } \\
\text { ikan }\end{array}$ & $\begin{array}{c}\text { Nilai } \\
\text { ADC }\end{array}$ \\
\hline Ikan Kalai & 585 \\
\hline Ikan Mas & 543 \\
\hline Ikan Lele & 583 \\
\hline Ikan Patin & 633 \\
\hline
\end{tabular}

Dari hasil pengujian nilai ADC sensor Photodioda didapatkan nilai ADC untuk air kolam yang diambil dari kolam sipil didapatkan nilai ADC yaitu 543 dan kemudian untuk selanjutnya diberikan tanah liat sedikit demi sedikit sampai pada titik keruh air didapatkan nilai ADC yaitu 589. Rumus yang digunakan untuk menguji dengan nilai $\mathrm{ADC}$ yaitu $\mathrm{ADC}=\mathrm{Vin} /(\mathrm{Vref} / 1023)$. Untuk pengujian berdasarkan jenis ikan saya melakukan pengujian pada peternakan ikan yang berlokasi di Jalan Sawah Laing Balaibaru Kecamatan Kuranji Kota Padang Sumatera Barat. Berdasarkan dari pengujian yang dilakukan didapatkan tingkat kekeruhan tertinggi pada kolam ikan patin dengan nilai ADC yaitu 633, Sedangkan tingkat kekeruhan terendah pada kolam ikan mas dengan nilai ADC 543.

\subsection{Pengujian Motor DC}

Hasil Pengujian motor untuk membuka pintu dapat dilihat pada tabel 4 .

Tabel 4. Hasil pengujian Motor DC untuk membuka pintu

\begin{tabular}{ccc}
\hline No. & $\begin{array}{c}\text { Pergerakan pintu } \\
\text { air }\end{array}$ & $\begin{array}{c}\text { Waktu } \\
\text { yang } \\
\text { dibutuhkan }\end{array}$ \\
\hline 1 & $0,5 \mathrm{~cm}$ & 10 detik \\
\hline 2 & $1 \mathrm{~cm}$ & 20 detik \\
\hline 3 & $1,5 \mathrm{~cm}$ & 30 detik \\
\hline 4 & $2 \mathrm{~cm}$ & 40 detik \\
\hline 5 & $2,5 \mathrm{~cm}$ & 50 detik \\
\hline 6 & $3 \mathrm{~cm}$ & 60 detik \\
\hline 7 & $3,5 \mathrm{~cm}$ & 70 detik \\
\hline 8 & $4 \mathrm{~cm}$ & 80 detik \\
\hline 9 & $4,5 \mathrm{~cm}$ & 90 detik \\
\hline 10 & $5 \mathrm{~cm}$ & 100 detik \\
\hline
\end{tabular}

Tabel 4. Hasil pengujian Motor DC untuk menutup pintu

\begin{tabular}{|c|c|c|c|}
\hline No. & $\begin{array}{c}S P \\
\text { (Set Point) }\end{array}$ & $\begin{array}{l}\text { Air yang } \\
\text { diberikan }\end{array}$ & Waktu \\
\hline 1 & $24 \mathrm{~cm}$ & \multirow{6}{*}{$25 \mathrm{~cm}$} & 2 detik \\
\hline 2 & $22 \mathrm{~cm}$ & & 3 detik \\
\hline 3 & $20 \mathrm{~cm}$ & & 4 detik \\
\hline 4 & $18 \mathrm{~cm}$ & & 5 detik \\
\hline 5 & $16 \mathrm{~cm}$ & & 5,5 detik \\
\hline 6 & $12 \mathrm{~cm}$ & & 6,5 detik \\
\hline 7 & $18 \mathrm{~cm}$ & \multirow{5}{*}{$20 \mathrm{~cm}$} & 2 detik \\
\hline 8 & $16 \mathrm{~cm}$ & & 3 detik \\
\hline 9 & $14 \mathrm{~cm}$ & & 4 detik \\
\hline 10 & $12 \mathrm{~cm}$ & & 5 detik \\
\hline 11 & $11 \mathrm{~cm}$ & & 5,5 detik \\
\hline
\end{tabular}

Dari data diatas didapatkan analisa bahwa motor membutuhkan waktu yang berkisar 10 detik setiap 0,5 $\mathrm{cm}$. Dan dengan pengujian kontrol pintu air kolam untuk mencapai tinggi yang diinginkan tidak terlalu lama sehingga pengujian pada motor untuk membuka pintu sangat efisien karena dengan waktu yang dibutuhkan untuk membuka pintu lebih mudah mengontrol air yang ada di dalam kolam. Jika motor membuka pintu terlalu cepat maka air yang didalam kolam akan cepat berkurang sehingga air yang ada didalam kolam bisa kurang dari nilai SP yang diberikan.

\section{KESIMPULAN}

Setelah dilakukan pengambilan data dan percobaan alat secara langsung dapat diambil kesimpulan sebagai berikut :

1. Jarak jangkauan sensor ultrasonik memiliki rata-rata error $1,67 \mathrm{~cm}$.

2. Hasil uji nilai ADC sensor photodioda yaitu pada air jernih 543 sampai pada titik keruh tertinggi pada 589

3. Motor pembuka pintu membutuhkan waktu 10 detik untuk membuka pintu setiap $0,5 \mathrm{~cm}$ agar air yang dikontrol sehingga air tersebut bisa mencapai nilai yang diinginkan dengan tepat

\section{.REFERENSI}

[1[1]. Maidi Rizki, Rahyul Amri. Perancangan Kontrol dan Monitoring Level Ketinggian Air di Waduk Bagian Hulu Untuk Meningkatkan Efektifitas Kinerja PLTA Koto Panjang. Jom FTEKNIK Volume 3 No. 1 Februari 2016, hal 1-6.

[2].Heki Apriyanto..Rancang Bangun Pintu Air Otomatis Menggunakan Water Level Float Switch Berbasis Mikrokontroler. Jurnal SISFOKOM, Volume 04, Nomor 01, Maret 2015, hal 22-27.

[3]. Abdul Fatah Maemunnur, Goib Wiranto, Waslaluddin Waslaluddin. Rancang Bangun Sistem Alat Ukur Turbidity Untuk Analisis Kualitas Air Berbasis Arduino Uno. Jurnal Online Fisika Fibusi Vol 4, No 1 (2016).

[4] Dina Mulya Siltri, Yohandri, Zulhendri Kamus. Pembuatan Alat Ukur Salinitas Dan Kekeruhan Air Menggunakan Sensor Elektroda Dan LDR. Jurnal Sainstek Vol. VII No.2: 126-139, Desember 2015

[5] Fauzi Amani, Kiki Prawiroredjo. Alat Ukur Kualitas Air Minum Dengan Parameter Ph, Suhu, Tingkat Kekeruhan, Dan Jumlah Padatan Terlarut. JETri, Volume 14, Nomor 1, Agustus 2016, Halaman 49 - 62, ISSN 1412-0372.

[6] Prerana ; Mangalpady R. Shenoy ; Bishnu P. Pal ; Banshi D. Gupta. Design, Analysis, and Realization of a Turbidity Sensor Based on Collection of Scattered Light by a Fiber-Optic Probe. IEEE Sensors Journal ( Volume: 12 , Issue: 1, Jan. 2012 ) Page(s): $44-50$

[7] YK Lu. Adaptive Fuzzy Integral Sliding Mode Regulator for Induction Motor Using Nonlinear Sliding Surface. IJPEDS International Journal of Power Electronics and Drive Systems. 2015; 5(4): 512-519. 